\title{
Ranking local climate policy: assessing the mitigation and adaptation activities of 104 German cities
}

\author{
Antje Otto ${ }^{1}$ (D) Kristine Kern $^{2,3}$ (D) Wolfgang Haupt $^{2}$ (D) Peter Eckersley $^{2,4}$ (D) \\ Annegret $\mathrm{H}$. Thieken ${ }^{1}$ (D)
}

Received: 14 January 2021 / Accepted: 8 June 2021/ Published online: 7 July 2021

(C) The Author(s) 2021, corrected publication 2021

\begin{abstract}
Climate mitigation and climate adaptation are crucial tasks for urban areas and can involve synergies as well as trade-offs. However, few studies have examined how mitigation and adaptation efforts relate to each other in a large number of differently sized cities, and therefore we know little about whether forerunners in mitigation are also leading in adaptation or if cities tend to focus on just one policy field. This article develops an internationally applicable approach to rank cities on climate policy that incorporates multiple indicators related to (1) local commitments on mitigation and adaptation, (2) urban mitigation and adaptation plans and (3) climate adaptation and mitigation ambitions. We apply this method to rank 104 differently sized German cities and identify six clusters: climate policy leaders, climate adaptation leaders, climate mitigation leaders, climate policy followers, climate policy latecomers and climate policy laggards. The article seeks explanations for particular cities' positions and shows that coping with climate change in a balanced way on a high level depends on structural factors, in particular city size, the pathways of local climate policies since the 1990s and funding programmes for both climate mitigation and adaptation.
\end{abstract}

Keywords Climate mitigation - Climate adaptation - Climate policy integration - Urban planning . City ranking · Germany

Antje Otto

anotto@uni-potsdam.de

1 Institute of Environmental Science and Geography, University of Potsdam, Karl-Liebknecht-Straße 24-25, 14476 Potsdam, Germany

2 Leibniz Institute for Research on Society and Space e.V. (IRS), Flakenstraße 29-31, 15537 Erkner, Berlin, Germany

3 Faculty of Social Sciences, Business and Economics, Åbo Akademi University, Vänrikinkatu 3 B, 20500 Turku, Finland

4 Nottingham Trent University, Newton Building, Goldsmith Street, Nottingham NG1 4BU, UK 


\section{Introduction}

It is now around three decades since the first local authorities - mostly big cities in the Global North - started to take action under the heading of climate change mitigation, although many only began to focus on adaptation initiatives several years later (Aylett 2015; Hunt and Watkiss 2011). In both fields of policy, however, urban areas are now seen as crucial players (Kousky and Schneider 2003; Rosenzweig et al. 2010; Sullivan et al. 2013). On the one hand, cities are sites of major greenhouse gas (GHG) emissions, whereas on the other hand they are particularly vulnerable to climate change impacts such as extreme weather events or sea level rise. These threats jeopardize the functioning of key infrastructures upon which densely populated urban areas rely, such as transport, utilities and healthcare services (IPCC Intergovernmental Panel on Climate Change 2014). Furthermore, in contrast to some nation states, cities are often seen as 'willing and able to take action' (Rosenzweig et al. 2010, p. 910).

Despite the importance of municipalities in climate policy and the extent to which some cities have engaged in the area, the literature suggests that their activities are sometimes constrained. First, adaptation efforts often lag behind mitigation activities (Guyadeen 2019; Heidrich et al. 2013; Lee et al. 2020). Second, the ambitions and activities of different cities on climate issues can vary enormously, with bigger municipalities often found to be more active (Araos et al. 2016; Reckien et al. 2015; Salvia et al. 2021). Third, the relationship between mitigation and adaptation on the ground is complex, involving not only synergies but also trade-offs and rivalry (Grafakos et al. 2018, 2020; Hamin and Gurran 2009; Landauer et al. 2015; Sharifi 2020, 2021). City administrations often treat the two fields separately and develop distinct strategies for each of them (Göpfert et al. 2019a; Grafakos et al. 2020; Reckien et al. 2018), which rarely consider how they might be better integrated (Grafakos et al. 2020).

In this context, it is unclear whether forerunners in mitigation are also leading the adaptation field or whether some cities tend to focus on just one area. To investigate how mitigation and adaptation efforts relate to each other in differently sized cities, we need to assess their activities in both areas. The broad climate policy literature includes case studies of leading municipalities (e.g. Beatley 2012) and overviews of the approaches and plans of various different cities (Heidrich et al. 2013; Olazabal et al. 2014; Reckien et al. 2014, 2018; Salvia et al. 2021), as well as rankings for either mitigation (Salvia et al. 2021; Wang et al. 2020) or adaptation (Araos et al. 2016; ). However, scholars have only recently begun to examine how mitigation and adaptation may relate to each other (Göpfert et al. 2019 a; Grafakos et al. 2019, 2020; Landauer et al. 2019; Lee 2020; Pasimeni et al. 2019), and, to our knowledge, there is no existing framework to rank cities on both mitigation and adaptation. This gap might be explained by the challenges in selecting appropriate indicators and collecting robust and assessable data to measure and compare mitigation and adaptation activities. As previous studies have identified, assessing mitigation and (particularly) adaptation independently of each other is already quite challenging (Ford and Berrang-Ford 2016; Ford et al. 2015; Martire et al. 2018).

Taking up these methodological challenges, this paper develops an internationally applicable framework to rank both the mitigation and adaptation activities of 104 German cities and thereby provide an overview of the state of urban climate policy in the country. We chose Germany as a case for three reasons: First, the level of national support for mitigation and adaptation has been quite stable in Germany for more than 10 years (unlike, e.g. in the USA or Australia). Second, climate policy has remained voluntary for German municipalities 
(Bulkeley and Kern 2006): cities have never been obliged to develop local mitigation or adaptation strategies like in France or Denmark (Heidrich et al. 2016). Third, cities must publish their mitigation and adaptation plans on their websites if they were supported by national funding (Reckien et al. 2019 SI 3), which is often the case. Drawing on the results of our ranking exercise, existing studies and our knowledge of German cities, we seek explanations for the positions of certain municipalities. As such, the article provides an overview of the state of urban climate policy in German cities, suggests an internationally applicable framework to rank cities on climate policy and contributes to knowledge about the relationship between urban mitigation and adaptation policies.

\section{State of research}

There is substantial literature on multilevel climate governance, as scholars have sought to identify how different actors both within and across tiers address this issue (Bulkeley 2010; Eckersley 2018; Fuhr et al. 2018; Kern 2019; Jänicke and Wurzel 2019). Initially, this focused largely on 'forerunner' or 'pioneer' cases in the Global North (most of which were large and wealthy cities) and their approaches to climate mitigation, often highlighting how they sought to introduce more ambitious policies than national governments and even compete with each other in a 'race to the top' regarding environmental ambition (Emelianoff 2014). Later research examined cities in the Global South suggesting that their increased vulnerability to a changing climate might be leading them to adopt more ambitious adaptation policies (Bulkeley 2010; Araos et al. 2016). Regardless of a city's location, however, studies often come to similar conclusions regarding the key factors that support the development of ambitious policies: active local politicians, a supportive local community and - often crucially - the resources available to the municipality (Castan Broto and Bulkeley 2013; Araos et al. 2017).

Studies into municipal adaptation have flourished in recent years. Depending on the local situation, climate impacts can include increased frequencies and magnitudes of flooding, storms or heat waves; shifts in seasons and changes in average temperature and rainfall; as well as sea level rise. Scholars have sought to examine how technical and engineering approaches might reduce the risks of climate impacts and analysed the governance arrangements that emerge as a result of state and non-state collaboration (Measham et al. 2011; Mees et al. 2012; Davoudi et al. 2013; Massey and Huitema 2016). Adaptation planning is a very complex phenomenon, as it requires public institutions to prepare for events that are highly unpredictable in terms of their timing and magnitude (Eckersley et al. 2018). Yet, climate impacts pose a particular risk to the interdependent network of systems and infrastructure that underpin urban living (Nicholls et al. 2008; Rosenzweig et al. 2010; World Bank 2010; IPCC Intergovernmental Panel on Climate Change 2014), and therefore we might expect cities to be increasingly active in this area.

However, local climate mitigation and adaptation formed two relatively independent research areas, with the latter focused on a more general debate around mainstreaming into existing strategies (e.g. Runhaar et al. 2017). Scholars have only recently sought to examine both issues simultaneously and study the interaction, interplay and integration of local mitigation and adaptation policies (Grafakos et al. 2020; Lee et al. 2020). These discussions 
identified synergies and co-benefits as well as trade-offs and conflicts between mitigation and adaptation (Grafakos et al. 2018, 2020; Hamin and Gurran 2009; Landauer et al. 2015; Sharifi 2020, 2021). They emphasize the mitigation-adaptation nexus, focus on the organizational institutionalization of climate mitigation and adaptation policies, develop indicators for the level of integration, discuss the role of national mandates and focus on sectoral policies (Keskitalo et al. 2016; Reckien et al. 2018; Grafakos et al. 2019, 2020; Göpfert et al. 2019a, b, 2020; Lee et al. 2020; Landauer et al. 2019).

Recent studies show, for example, that national mandates matter (e.g. Keskitalo et al. 2016). In addition, cities with an established monitoring system for mitigation are more likely to adopt adaptation policies, and established mitigation policies are more important than local climate risks and vulnerabilities when cities decide on joining municipal adaptation networks like Mayors-ADAPT (Lee et al. 2020). However, most recent research has focused on only a limited number of cities (Landauer et al. 2019), or examined cities in specific countries such as Italy and Spain (Pasimeni et al. 2019), or compared municipalities in those countries that have national mandates (Denmark) with those that do not (Finland) (Keskitalo et al. 2016). Various studies on cities in the EU include Germany, but the number of cities is not always sufficient or representative (e.g. Grafakos et al. 2020). Also, some studies focus on specific institutional features such as climate change committees (Göpfert et al. 2019a) or on the characteristics of existing plans such as the difference between dedicated and mainstreaming approaches (Reckien et al. 2019).

Most research so far has focused on strategies and plans, perhaps because they provide an accessible source of information on cities' climate activities. For example, Grafakos et al. $(2019,2020)$ developed a framework to analyse the integration of mitigation and adaptation in climate plans. They applied the Urban Climate Change Integration Index which takes different stages of urban climate planning into account and is based on 25 variables, of which 9 relate directly to the integration of both policy fields. According to their scores, cities were classified into early-stage, moderate and advanced integrators (Grafakos et al. 2020). Analysing 147 local climate action plans in Europe, they conclude that most plans show a moderate amount of integration and just a quarter cover synergies or conflicts between mitigation and adaptation.

This paper aims to contribute to this strand of literature on the relationship between mitigation and adaptation by developing an index to rank cities on climate policy. A first step towards creating a framework to assess climate mitigation and adaptation involves developing sets of relevant indicators. This could involve drawing on the principles underpinning existing ranking systems. However, developing appropriate indicators to rank cities against each other is not an easy task, due to unique local contexts and multiple external variables over which municipalities have no control. Indeed, the methodologies upon which urban sustainability ranking systems are based are often weak and lack transparency (Meijering et al. 2014) or rely on proxy indicators that do not provide a comprehensive assessment of cities' activitiesparticularly in the area of adaptation (Hanson et al. 2011; Balicia et al. 2012). Notwithstanding these concerns, we developed indexes to assess both mitigation and adaptation at the urban level and then applied them to 104 German cities to provide a broad and consistent overview of the activities they are undertaking in both fields. Therefore, this paper suggests an approach to compare the climate activities of a large number of cities, which can help us better understand how both policy fields are interrelated. 
Table 1 City sample

\begin{tabular}{|c|c|c|c|}
\hline Group of cities & Characterization according to BBSR (2017) & $\begin{array}{l}\text { Number of cities } \\
\text { (as of } 31 \\
\text { Dec. 2017) }\end{array}$ & $\begin{array}{l}\text { Share of total German } \\
\text { population (as of } 31 \\
\text { Dec. 2017) }\end{array}$ \\
\hline Big city & $\begin{array}{l}\text { - Minimum of } 500,000 \text { inhabitants } \\
\text { - Including the three cities with functions of } \\
\text { federal states (Berlin, Hamburg, } \\
\text { Bremen) }\end{array}$ & 14 & $17 \%$ \\
\hline $\begin{array}{l}\text { Medium-sized } \\
\text { city }\end{array}$ & - Minimum of 100,000 inhabitants & 66 & $15 \%$ \\
\hline $\begin{array}{l}\text { Small } \\
\text { independent } \\
\text { city }\end{array}$ & $\begin{array}{l}\text { - Minimum of 50,000 inhabitants } \\
\text { - Independent from any county }\end{array}$ & 24 & $2 \%^{2}$ \\
\hline Total & & 104 & $34 \%$ \\
\hline
\end{tabular}

${ }^{1}$ https:/www.destatis.de/DE/ZahlenFakten/LaenderRegionen/Regionales/Gemeindeverzeichnis/Administrativ/ Aktuell/05Staedte.html

${ }^{2}$ This small share of the overall population is because we selected only the 24 cities that are independent from any county. In all of Germany, there are many more cities with more than 50,000 and less than 100,000 inhabitants.

\section{Methods}

\subsection{City sample}

Our city sample consists of three official types of German cities classified by their size (BBSR 2017; see Table 1; Fig. 6); each city has at least 50,000 inhabitants. In total, we selected 104 cities, which represent $34 \%$ of the German population (as of $31 \mathrm{Dec} 2017$; for a list of all cities, see Supplementary Information (SI) 1). To ensure comparability, we only include cities that are not associated with a county ('kreisfrei') within the group of smaller cities, as these 'independent' cities are responsible for both county and district authority functions and therefore have a similar administrative scope as big German cities. A similar sample was used by Thieken et al. (2018) and Dierck (2016).

\subsection{Ranking and data analysis}

We developed a comparable ranking approach for both mitigation and adaptation, according to three main criteria. First, (sub-)indicators need to be highly relevant to the state of urban climate mitigation or adaptation. Second, appropriate (sub-)indicators must be available for both topics. Third, the data on the (sub-)indicators should be openly accessible, ideally for all (or most of the) 104 cities, and researchable within a reasonable timeframe.

We assessed both mitigation and adaptation along three dimensions, each of which comprise one-third of the 100 maximal attainable score for each ranking. The three dimensions comprise several indicators (Figs. 1 and 2):

- Dimension A: Local political will and commitment, including indicators related to (a) membership of climate-related city networks and (b) participation in climate-related certification programmes and competitions. Such indicators have been used elsewhere to illustrate higher levels of political ambition for climate action (e.g. Toly 2008; Lee and Koski 2015; Lesnikowski et al. 2020). 
- Dimension B: Urban climate mitigation and adaptation plans, including the indicators (a) existence of a plan or strategy, (b) year of publishing the first plan and (c) (number of) updates to the plan (see Reckien et al. $(2014,2018)$ for examples of where previous studies have examined the existence and age of mitigation and adaptation plans as a way to assess cities' climate policies).

- Dimension C: Climate adaptation and mitigation ambitions. For mitigation, this included GHG emission reduction targets and the timeframe for reaching these targets. For adaptation, this covered the extent of measures within climate adaptation plans (see Fig. 2). Previous studies have sought to assess the level of adaptation and mitigation ambition using similar metrics (Woodruff and Stults 2016; Salvia et al. 2021).

These indicators provide the overall framework within which we then developed several sub-indicators specific to climate mitigation or adaptation. Our assessment approach is shown in Figs. 1 and 2 (for details on data sources, see SI 2 and 3).

Our analysis revealed more comprehensive and detailed information on the mitigation subindicators than those relating to adaptation. Furthermore, we had to judge mitigation and adaptation ambition (dimension $\mathrm{C}$ in Figs. 1 and 2) quite differently. In the case of mitigation, we focused on GHG reduction targets, which is straightforward to identify but may nonetheless provide a superficial and misleading picture of the extent to which cities are trying to achieve their objectives. Tracking achievements in adaptation is more challenging because needs differ locally, the effects of measures might only become apparent many years into the future and there is a lack of good data (Ford and Berrang-Ford 2016; Ford et al. 2015). Thus, we analysed the contents of adaptation plans to identify and rate the extent and diversity of planned adaptation measures to award a score against this metric (see Figs. 1 and 2 for details).

Based on the mitigation and adaptation scores, we undertook correlation and cluster analyses to better understand the similarities and differences between mitigation and adaptation policies. A hierarchical cluster analysis was performed using the Ward method with squared Euclidian distances. As input variables, the z-transformed scores of the six subdimensions introduced in Figs. 1 and 2 were taken. The dendrogram was used to identify a robust number of clusters.

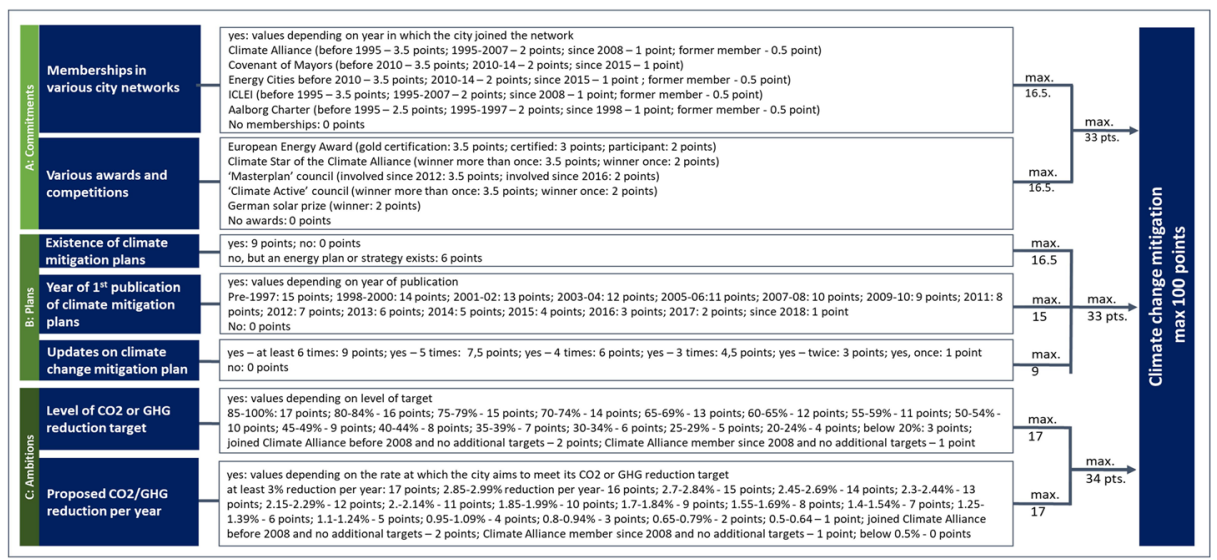

Fig. 1 Climate change mitigation ranking: indicators and their scores [state of assessment: 31 of December 2018] 


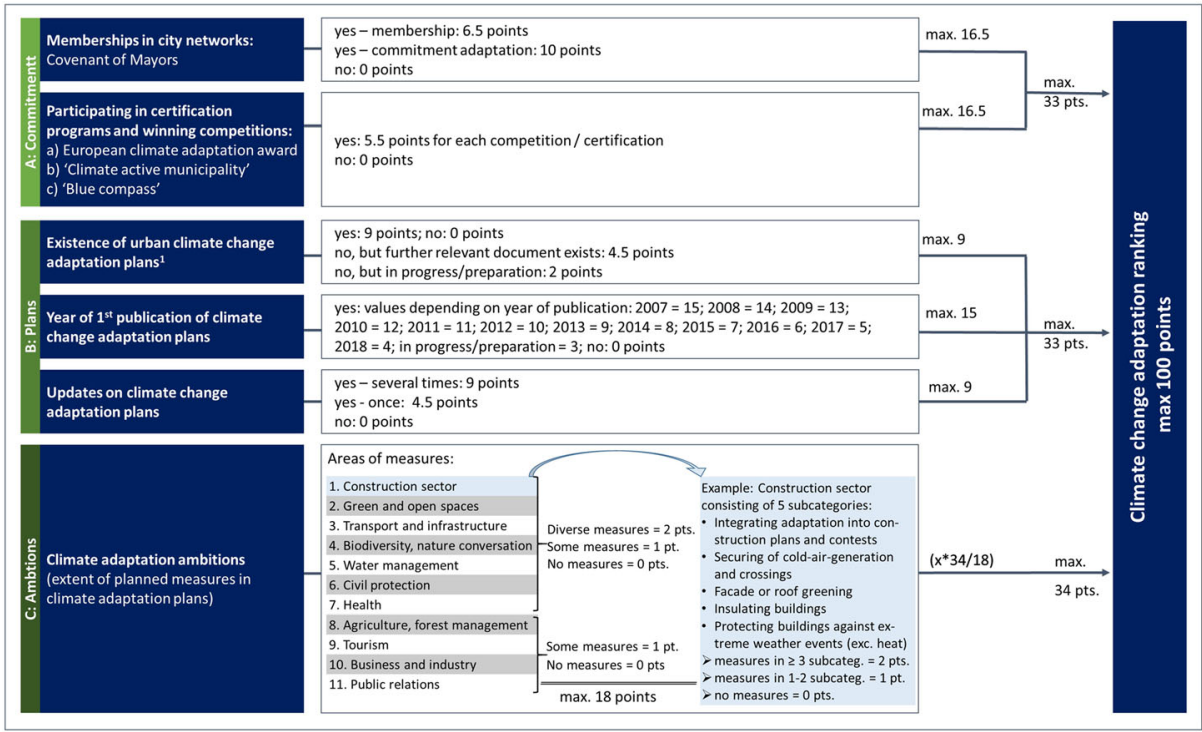

Fig. 2 Climate change adaptation ranking: indicators and their scores [state of assessment: 31 of December 2018]

\section{Findings}

Figure 3 shows all 104 cities in descending order of their total scores on mitigation or adaptation. We ranked each city separately for the two policy fields; the individual scores are presented in SI 1. Figure 3 shows that mitigation is a more advanced policy field in

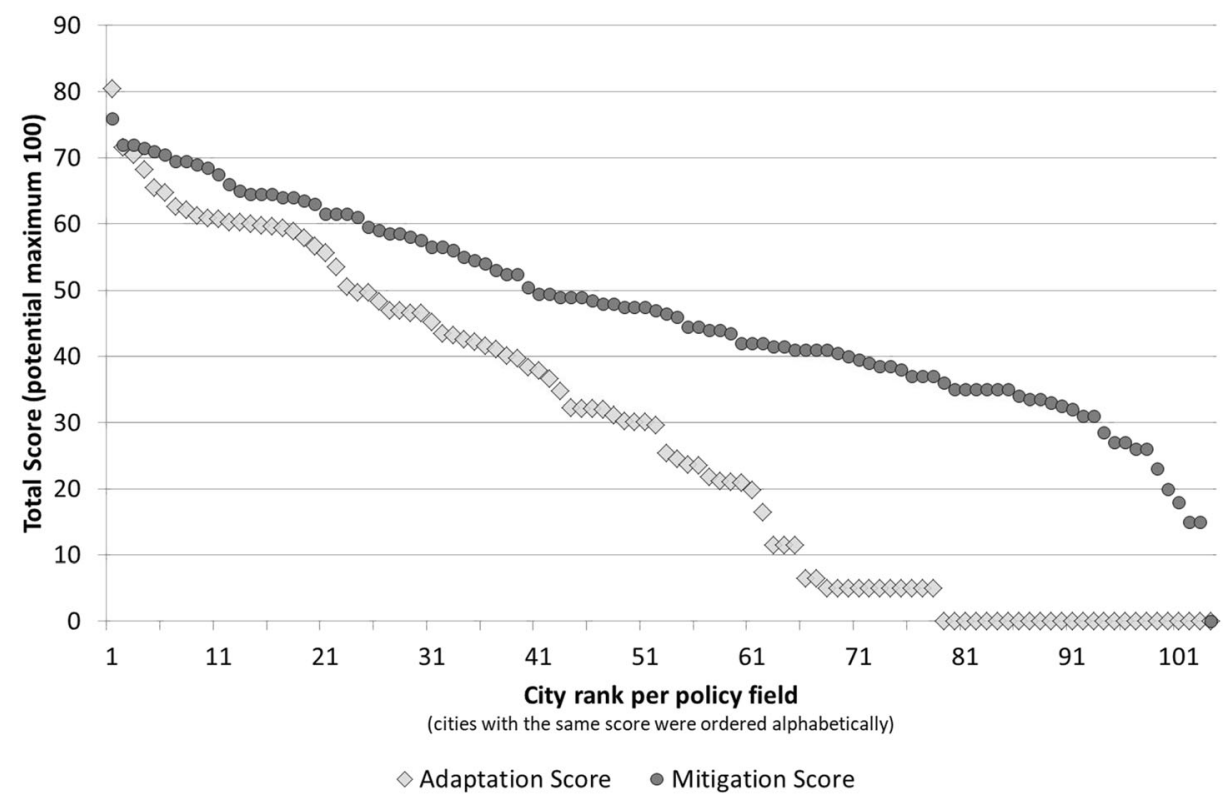

Fig. 3 Distribution of all 104 German cities according to their total scores on mitigation and adaptation (the outcomes per city are presented in SI 1). 
Table 2 Overview of climate mitigation and adaptation scores and activities

\begin{tabular}{lll}
\hline & Mitigation & Adaptation \\
\hline Lowest score & 0 & 0 \\
Highest score & 76 & 80.5 \\
Total average value & 46.9 & 27.7 \\
Coefficient of variation & $32 \%$ & $87 \%$ \\
Members of city networks (dimension A) & $81.7 \%$ & $34.6 \%$ \\
Certification programmes or competitions (dimension A) & $61.5 \%$ & $14.4 \%$ \\
Published plan by the end of 2018 (dimensions B and C) & $99 \%$ & $59 \%$ \\
\hline
\end{tabular}

comparison to adaptation: only one city received a mitigation score of zero, whereas this was the case for 26 cities in the area of adaptation. The range of scores for mitigation is also smaller than for adaptation, while the average score is higher (see Table 2).

\subsection{Ranking on climate mitigation}

In terms of their climate mitigation activities, the 104 cities range from 0 to 76 points (see Fig. 3 ; Table 2), with an average value of 46.9 points and a coefficient of variation of $32 \%$. Eightyfive $(81.7 \%)$ cities were members of climate mitigation-related city networks (dimension A): the Climate Alliance was by far the most popular network, with 77 (74\%) cities as members. Sixty-four cities (i.e. $61.5 \%$ ) took part in certification programmes or competitions (dimension A), and 103 (99\%) had published a mitigation plan by the end of 2018 (dimensions B and C).

The best ranking city is Freiburg, with 76 out of 100 points, followed by Bonn and Münster with 72 points each (Table 3; for more details, see SI 1). All three belong to the group of medium-sized cities. Within the 20 best scoring municipalities, there are ten medium-sized

Table 3 Twenty best scoring cities concerning climate mitigation (note that some cities achieved the same outcome and were ranked equally, e.g. on ranks 14 to 16 )

\begin{tabular}{lllll}
\hline Rank & City & City type & Number of inhabitants (as of 31 Dec 2017) & Mitigation score \\
\hline 1 & Freiburg & Medium & 229,636 & 76.0 \\
2 & Bonn & Medium & 325,490 & 72.0 \\
2 & Münster & Medium & 313,559 & 72.0 \\
4 & Stuttgart & Big & 632,743 & 71.5 \\
5 & Mainz & Medium & 215,110 & 71.0 \\
6 & Bremen & Big & 568,006 & 70.5 \\
7 & Frankfurt (Main) & Big & 746,878 & 69.5 \\
7 & Hannover & Big & 535,061 & 69.5 \\
9 & Heidelberg & Medium & 160,601 & 69.0 \\
10 & Berlin & Big & $3,613,495$ & 68.5 \\
11 & Rostock & Medium & 208,409 & 67.5 \\
12 & Bottrop & Medium & 117,364 & 66.0 \\
13 & Nuremberg & Big & 515,201 & 65.0 \\
14 & Bielefeld & Medium & 332,552 & 64.5 \\
14 & Essen & Big & 583,393 & 64.5 \\
14 & Kiel & Medium & 247,943 & 64.5 \\
17 & Kaiserslautern & Small independent & 99,684 & 64.0 \\
17 & Ulm & Medium & 125,596 & 64.0 \\
19 & Munich & Big & $1,456,039$ & 63.5 \\
20 & Emden & Small independent & 50,607 & 63.0 \\
\hline & & & &
\end{tabular}




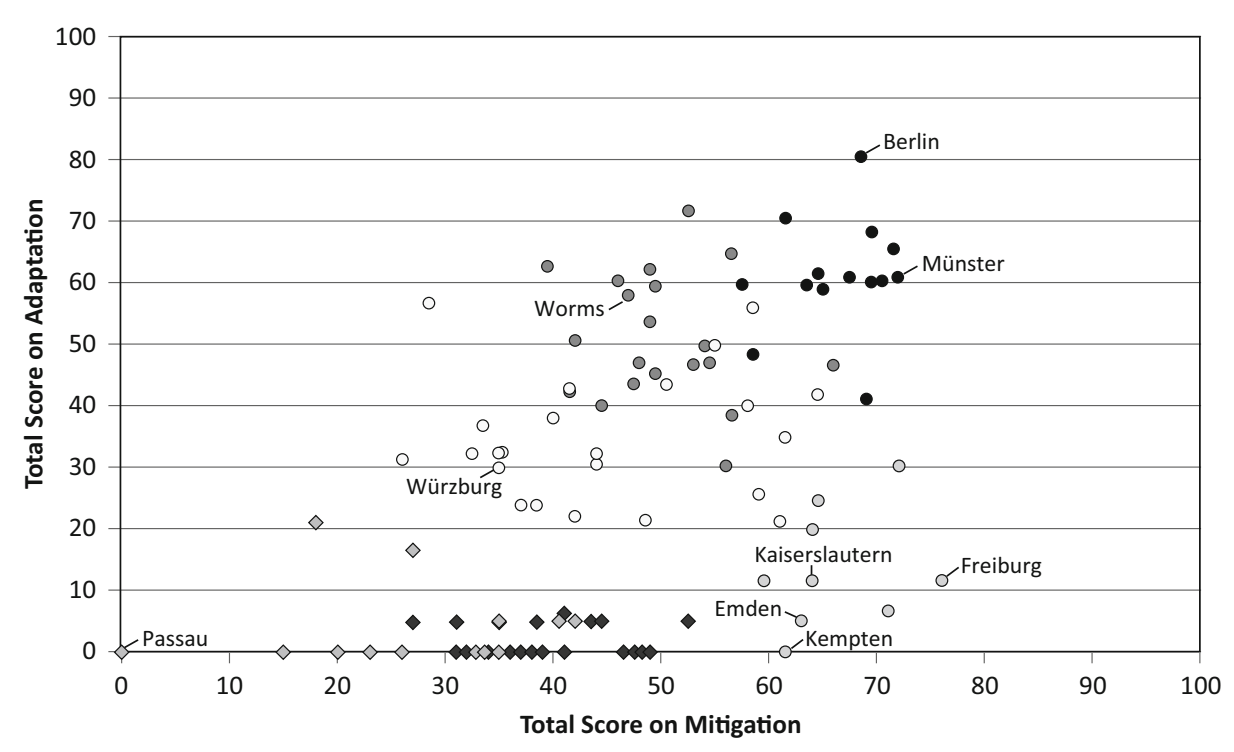

- Cluster 1 OCluster 2 OCluster 3 OCluster $4 \diamond$ Cluster $5 \diamond$ Cluster 6

Fig. 4 Scatter plot of the total scores on mitigation and adaptation scores of 104 German cities and their cluster affiliation (the outcomes per city are presented in SI 1; some cities mentioned in the text are shown).

cities, eight big cities and only two small independent cities $^{1}$ (see Table 3). Just six of the 14 largest cities (36\%) — namely Cologne, Dortmund, Dresden, Dusseldorf, Hamburg and Leipzig - are not among these 20 best scoring cities. The first small city, Kaiserslautern, was ranked 17 th (Table 3 ).

Except for Passau, all cities showed a measurable degree of activity in mitigation concerning our indicators and received a score higher than ten points (see Fig. 3). Moreover, only four cities received a score lower than 20 and eleven lower than 30 points. All of the lowest-ranked 15 cities are relatively small: seven are medium-sized cities and eight are small cities, with Paderborn (149,075 inhabitants) being by far the largest among them. Indeed, a correlation analysis between the number of city inhabitants and its climate mitigation performance revealed a weak, though significant, correlation $(r=0.37 ; \mathrm{p}=0.01)$.

\subsection{Ranking on climate adaptation}

Concerning climate adaptation, the 104 cities range between 0 and 80.5 points (see Fig. 4; Table 2) with an average value of 27.7 points and a coefficient of variation of $87 \%$. Thus, adaptation is a very heterogeneous field. Thirty-six (34.6\%) were members of climate adaptation-related city networks, and fifteen (14.4\%) took part in certification programmes or competitions (both dimension A). Sixty-one cities (59\%) had published an adaptation plan by the end of 2018 (dimensions B and C).

The best ranking city is Berlin, which achieved 80.5 out of 100 points and thus nine points more than second-placed Karlsruhe (Table 4; for more details, see SI 1). Within the 20 best scoring cities, there are eleven big cities and eight medium-sized cities, but just one small city,

\footnotetext{
${ }^{1}$ We subsequently refer to this group as 'small cities'.
} 
Table 4 Twenty best scoring cities concerning climate adaptation

\begin{tabular}{lllll}
\hline Rank & City & City type & Number of inhabitants (as of 31 Dec 2017) & Adaptation score \\
\hline 1 & Berlin & Big & $3,613,495$ & 80.5 \\
2 & Karlsruhe & Medium & 311,919 & 71.6 \\
3 & Hamburg & Big & $1,830,584$ & 70.4 \\
4 & Frankfurt (Main) & Big & 746,878 & 68.2 \\
5 & Stuttgart & Big & 632,743 & 65.6 \\
6 & Dresden & Big & 551,072 & 64.7 \\
7 & Oberhausen & Medium & 211,422 & 62.7 \\
8 & Cologne & Big & $1,080,394$ & 62.1 \\
9 & Essen & Big & 583,393 & 61.3 \\
10 & Rostock & Medium & 208,409 & 60.9 \\
11 & Münster & Medium & 313,559 & 60.8 \\
12 & Offenbach & Medium & 126,658 & 60.3 \\
13 & Bremen & Big & 568,006 & 60.2 \\
14 & Hannover & Big & 535,061 & 60.1 \\
15 & Aachen & Medium & 246,272 & 59.8 \\
16 & Munich & Big & $1,456,039$ & 59.7 \\
17 & Duisburg & Medium & 498,110 & 59.4 \\
18 & Nuremberg & Big & 515,201 & 58.9 \\
19 & Worms & Small independent & 83,081 & 57.9 \\
20 & Jena & Medium & 111,099 & 56.6 \\
\hline
\end{tabular}

Worms, which was placed 19th. Just three of the 14 largest cities (Dortmund, Dusseldorf and Leipzig) are not in the top 20 (see Table 4).

Table 5 Twenty best scoring cities concerning climate policy performance (mitigation and adaptation combined)

\begin{tabular}{lllll}
\hline Rank & City & $\begin{array}{l}\text { City } \\
\text { size }\end{array}$ & $\begin{array}{l}\text { Number of } \\
\text { inhabitants } \\
\text { (as of 31 Dec 2017) }\end{array}$ & $\begin{array}{l}\text { Mean min-max-scaled score (i.e. each original score } \\
\text { was scaled to the maximum and minimum score per } \\
\text { policy field) }\end{array}$ \\
\hline 1 & Berlin & Big & $3,613,495$ & 95.1 \\
2 & Frankfurt & Big & 746,878 & 88.1 \\
& $\quad$ (Main) & & & \\
3 & Stuttgart & Big & 632,743 & 87.8 \\
4 & Münster & Medium & 313,559 & 85.2 \\
5 & Hamburg & Big & $1,830,584$ & 84.2 \\
6 & Bremen & Big & 568,006 & 83.8 \\
7 & Hanover & Big & 535,061 & 83.0 \\
8 & Rostock & Medium & 208,409 & 82.3 \\
9 & Essen & Big & 583,393 & 80.5 \\
10 & Nuremberg & Big & 515,201 & 79.3 \\
11 & Karlsruhe & Medium & 311,919 & 79.0 \\
12 & Munich & Big & $1,456,039$ & 78.8 \\
13 & Dresden & Big & 551,072 & 77.4 \\
14 & Aachen & Medium & 246,272 & 75.0 \\
15 & Potsdam & Medium & 175,710 & 73.1 \\
16 & Bottrop & Medium & 117,364 & 72.3 \\
17 & Heidelberg & Medium & 160,601 & 70.9 \\
18 & Cologne & Big & $1,080,394$ & 70.8 \\
19 & Duisburg & Medium & 498,110 & 69.5 \\
20 & Dusseldorf & Big & 617,280 & 68.5 \\
\hline & & & &
\end{tabular}


Table 6 Mean performance of mitigation and adaptation of the six clusters (Clu) shown in Figs. 4 and 5 and urban typology in climate policies

\begin{tabular}{|c|c|c|c|c|c|}
\hline $\mathrm{Clu}$ & $\begin{array}{l}\text { Number } \\
\text { of cities }\end{array}$ & $\begin{array}{l}\text { Average number of } \\
\text { inhabitants as of } 31 \\
\text { Dec } 2017\end{array}$ & $\begin{array}{l}\text { Average } \\
\text { total score } \\
\text { on } \\
\text { mitigation }\end{array}$ & $\begin{array}{l}\text { Average } \\
\text { total score } \\
\text { on } \\
\text { adaptation }\end{array}$ & Brief characterization \\
\hline 1 & 14 & 859,109 & 66.3 & 61.1 & $\begin{array}{l}\text { Very high scores on mitigation and } \\
\text { adaptation: balanced approaches on a } \\
\text { very high level (climate policy leaders) }\end{array}$ \\
\hline 2 & 20 & 309,114 & 50.1 & 51.0 & $\begin{array}{l}\text { High scores on mitigation and (very) high } \\
\text { scores on adaptation: balanced ap- } \\
\text { proaches on a high level (climate adap- } \\
\text { tation leaders) }\end{array}$ \\
\hline 3 & 9 & 173,111 & 66.2 & 13.4 & $\begin{array}{l}\text { Very high scores on mitigation and } \\
\text { relatively low scores on adaptation: } \\
\text { unbalanced approaches (climate } \\
\text { mitigation leaders) }\end{array}$ \\
\hline 4 & 23 & 168,909 & 44.7 & 34.6 & $\begin{array}{l}\text { Medium scores on mitigation and } \\
\text { adaptation: (relatively) balanced ap- } \\
\text { proaches on a medium level (climate } \\
\text { policy followers) }\end{array}$ \\
\hline 5 & 24 & 125,042 & 39.9 & 1.7 & $\begin{array}{l}\text { Low scores on mitigation commitments and } \\
\text { (almost) no action in adaptation: unbal- } \\
\text { anced approaches (climate policy late- } \\
\text { comers) }\end{array}$ \\
\hline 6 & 14 & 104,803 & 25.9 & 3.7 & $\begin{array}{l}\text { Low scores on mitigation commitments and } \\
\text { mitigation ambitions and (almost) no } \\
\text { action in adaptation: unbalanced ap- } \\
\text { proaches (climate policy laggards) }\end{array}$ \\
\hline All & 104 & 270,394 & 46.9 & 27.7 & \\
\hline
\end{tabular}

There are many cities with very low scores (see Fig. 3). The adaptation activities covered by our indicators are either largely or totally absent in about one-third of the 104 municipalities we studied: $37.5 \%$ (39 cities) gained fewer than ten points. One-quarter of the sample (i.e. 26 cities) did not receive any points at all. These cities have not developed an urban climate adaptation plan, nor have they participated in any climate adaptation-related city network or competition. Within the group of cities without any points, 14 are small cities and 12 are medium-sized cities. A correlation analysis estimating the role of inhabitants on climate adaptation performance revealed a moderate, though significant, correlation between city size and adaptation score $(\mathrm{r}=0.5 ; \mathrm{p}=0.01)$. Thus, city size is more closely linked to urban adaptation than to mitigation.

\subsection{Comparing both rankings}

Notably, different cities lead on mitigation compared to adaptation, although some feature in both top 20 lists (see Tables 3 and 4). To assess a city's general performance in climate policies, we calculated the average from the mitigation and adaptation scores. We also scaled their scores between the maximum and minimum in each field for two reasons. First, as we outlined (Table 2), cities received a broader range of scores for adaptation than for mitigation, even though the policy field of adaptation emerged after mitigation. Second, dimension $\mathrm{C}$ was assessed by rather different indicators in the two policy fields (see Figs. 1 and 2). 


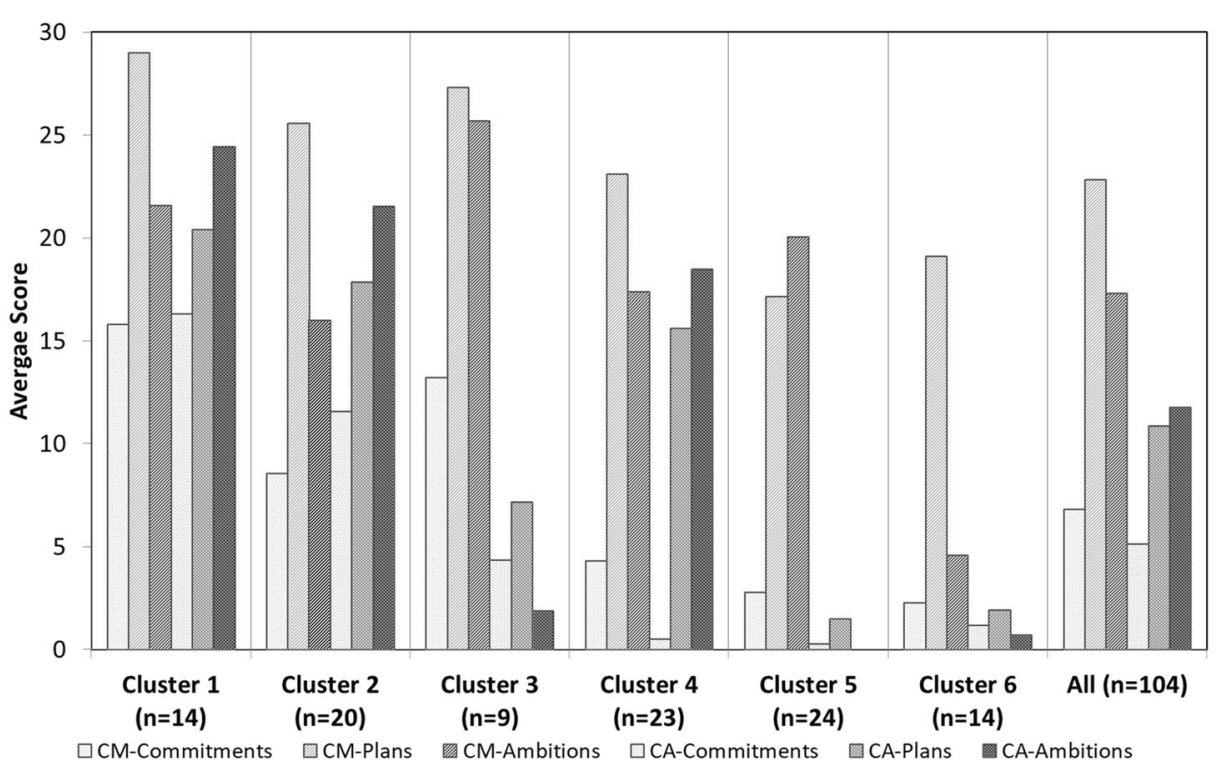

Fig. 5 Characteristics of the six clusters and the whole dataset concerning their average score on the subdimensions (A, B, C; see Figs. 1 and 2) in climate mitigation (CM) and climate adaptation (CA)

Table 5 shows the 20 cities that scored best when taking the average of the min-max-scaled scores of both policy fields. Within this top group, there are 12 big cities out of 14 in total (Dortmund and Leipzig are not part of this group) and eight medium-sized cities, i.e. no small city achieved a top position in this overall ranking. Ten cities, i.e. Berlin, Frankfurt/Main, Stuttgart, Münster, Bremen, Hanover, Rostock, Essen, Nuremberg and Munich, were already listed in both Tables 3 and 4 as being among the top 20 for climate mitigation and adaptation, respectively. Just two cities, Potsdam and Dusseldorf, were listed neither in Table 3 nor in Table 4 but achieved rank 15 and 20 in Table 5, respectively, indicating a balanced climate policy.

The Pearson correlation coefficient between the total scores on adaptation and mitigation amounts to $0.52(\mathrm{p}<0.001)$, indicating that cities that have an advanced mitigation policy also tend to have some sort of adaptation strategy. This positive relation between the two fields of climate policies is further illustrated by Fig. 4. However, Table 5 already indicates that there are different approaches to climate policies. Therefore, we performed a cluster analysis based on all six sub-dimensions (rather than just the two fields of climate mitigation and adaptation) and identified six clusters for closer analysis (see Fig. 4) from the dendrogram (not shown). These are characterized in Table 6 by their mean total scores and their average number of inhabitants, as well as in Fig. 5 by the average values of the indicators that we used as input variables in the cluster analysis. In Table 6 , the clusters were ordered by the average city size (largest to smallest) and numbered accordingly. Together with the findings from Fig. 5, we derived a typology of cities.

Cities in cluster 1 have above-average scores in all sub-dimensions for mitigation and adaptation (Fig. 5). Consequently, cities of this cluster qualify as climate policy leaders. Many cities in this group appear in the list of the top 20 cities (Table 5). They managed to develop balanced approaches to mitigation and adaptation and show a high level of commitment in both areas. Examples include the three city states (Berlin, Hamburg, Bremen), most of the 

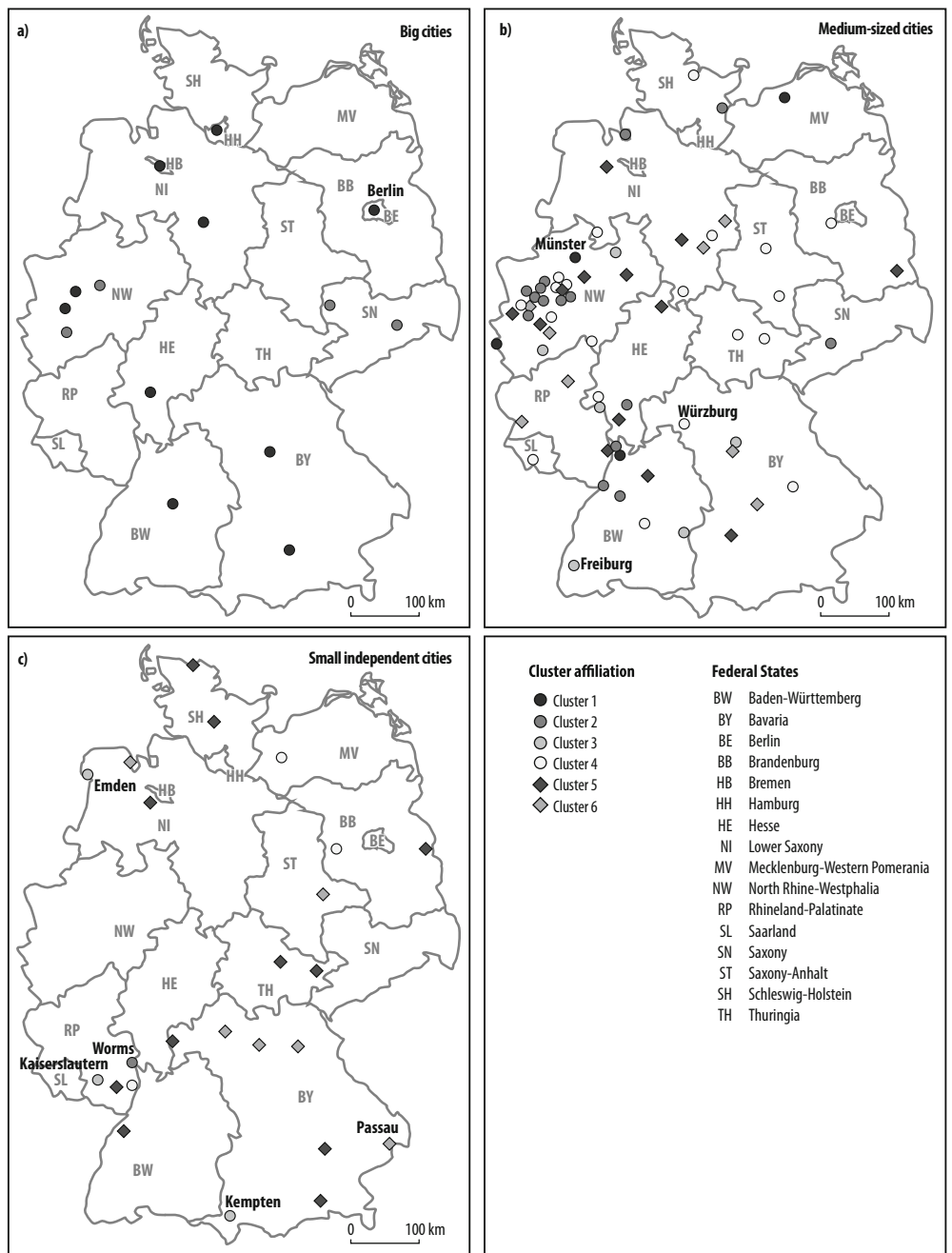

Fig. 6 Maps showing the distribution of 104 German cities with their cluster affiliation for each city size type (the outcomes per city are presented in SI 1; some cities mentioned in the text are shown)

biggest cities (including the state capitals Frankfurt/Main, Stuttgart, Hanover and Munich) and also a few medium-sized cities (e.g. Münster and Rostock) (Table 5, Figs. 4, 5 and 6).

In cluster 2, scores for all mitigation and adaptation sub-dimensions are still above average, i.e. these cities also show balanced approaches at a high level. However, since they score higher for adaptation than mitigation, this cluster contains climate adaptation leaders. These cities score lower than the top performers but have developed innovative adaptation-oriented approaches and show at least a moderate performance in the area of mitigation. Apart from a few big cities (e.g. Cologne, Dresden), this group comprises mainly medium-sized municipalities (e.g. Karlsruhe, Offenbach) as well as the small city of Worms. Half of these 20 cities are located in North Rhine-Westphalia (see Fig. 6).

With just nine cities, cluster 3 forms the smallest group. The most striking feature is the very high performance in mitigation, while adaptation is far below average. Hence, these cities 
are climate mitigation leaders. For sub-dimension $\mathrm{C}$, 'ambitions' for mitigation, they score higher than any other group. This cluster consists of some medium-sized cities (e.g. Freiburg, Mainz, Ulm and Erlangen) and three small cities (Emden, Kempten and Kaiserslautern) (see Fig. 6).

In contrast, cities in cluster 4 show again more balanced scores for both fields, i.e. average scores for mitigation and above-average scores for adaptation, except for the sub-dimension A on commitments (Fig. 5). Thus, we termed them climate policy followers. Though a few cities in this cluster (in particular Potsdam, Kiel and Magdeburg) are very close to the climate policy leaders, most are not known for their bold initiatives or their engagement in international cooperation and networking. As Fig. 6 shows, nearly every member of this relatively big and heterogeneous group of 23 cities is medium-sized municipalities, except three smaller cities (Brandenburg/Havel, Schwerin and Speyer).

Finally, cities in clusters 5 and 6 show a relatively low performance. Average scores in cluster 5 (which has 24 cities) and cluster 6 (14 cities) are far below the mean for adaptation and slightly below average for mitigation (Fig. 5). The clusters differ from each other with respect to sub-dimension $\mathrm{C}$, 'ambitions' in mitigation, for which scores are considerably higher in cluster 5 . More than half of the cities in this cluster have set ambitious long-term mitigation goals for 2050, although most have not set adequate interim goals. Thus, this cluster of relatively small cities (11 of the 24 are small cities; see Fig. 6) contains climate policy latecomers. Although almost all cities in cluster 6 (with Passau as the only exception) have developed some sort of mitigation strategy, they tend not to set any emission reduction goals, and only a few have started to develop an adaptation strategy. Thus, we named them climate policy laggards. Many of these cities are also relatively small (six of the 14 have fewer than 100,000 inhabitants), and six of them are located in Bavaria (see Fig. 6).

\section{Discussion}

In line with the literature, our results show that city size plays a key role in shaping local climate policy (Araos et al. 2016; Haupt et al. 2020; Kern et al. 2005; Reckien et al. 2018; Salvia et al. 2021). Big cities and metropolitan areas have more capacity to develop local climate policies than smaller cities (Haupt 2020; Kern 2019; Reckien et al. 2015). Out of the 14 biggest German cities (those with more than 500,000 inhabitants), ten can be classified as climate policy leaders (cluster 1) and four as climate adaptation leaders (cluster 2).

In contrast, small cities score considerably lower and tend to be latecomers or laggards (Kern 2020). None of the smaller cities qualifies as a climate policy leader. With this in mind, we might expect that cities and towns that are smaller than the ones we examined would show even less initiative, although the lack of research into the activities of such places means that we are not yet in a position to confirm whether this is the case (Haupt et al. forthcoming). However, our study does contain a few examples of small cities that were able to join the climate policy followers in cluster 4 (Schwerin, Brandenburg/Havel and Speyer) or have even become leaders in climate mitigation in cluster 3 (Emden, Kaiserslautern and Kempten) or adaptation in cluster 2 (Worms) (Table 3; Fig. 6).

The group of medium-sized cities (100,000-500,000 inhabitants), which account for almost two-thirds of our sample, is far more diverse (see Table 6). Mid-sized cities show up in all six clusters, ranging from a few top performers (e.g. Münster, Rostock and Karlsruhe) to cities that show a very poor mitigation performance and (almost) no action in the area of adaptation (e.g. 
Bergisch-Gladbach, Salzgitter and Wilhelmshaven). Münster and Rostock are the only midsized cities to appear on all three top 20 lists (Tables 3, 4 and 5).

Since the development of strategies for mitigation preceded that of adaptation by at least 15 years, it is perhaps not surprising that the average score for the former is higher than the latter (Fig. 3, Table 2; see also Reckien et al. 2018). However, climate policy leaders are most successful in developing a balanced approach of mitigation and adaptation at a very high level (Difu - Deutsches Institut für Urbanistik 2015, 2017, 2020). They have focused on new climate policy issues, revised their mitigation strategies several times and developed adaptation strategies, often supported by external funding and participation in research projects. The climate policy leaders in cluster 1 have developed various ways of integrating adaptation into existing organizational structures and strategies, working towards what Göpfert et al. (2019b) term a coherent 'adaptigation' approach that builds capacity in both aspects of climate policy. In Münster, for example, mitigation policy started in 1995, when the city established its Coordination Office for Climate and Energy, published its first action programme for climate mitigation and joined the Climate Alliance. In 2015, Münster introduced its first adaptation strategy, which was already in preparation when a severe pluvial flood affected almost the entire city in 2014 (Spekkers et al. 2017). Today, two out of eight employees of the Coordination Office focus solely on climate adaptation.

Other studies suggest that the group of forerunner cities, including Berlin, Frankfurt/Main, Stuttgart, Munich and Heidelberg, has not changed much since the 1990s (see, e.g. Kern et al. 2005; Monstadt 2007; Berghausen 2012; Emilianoff 2013; Heinelt and Lamping 2015). As big forerunner cities have stayed ahead for almost 30 years, we argue that performance in climate policy is path-dependent. In contrast to climate policy followers, latecomers and laggards, almost all leading cities joined transnational networks from the outset and still exhibit a very international orientation and reputation (Kern et al. 2005; Kern and Bulkeley 2009). By continuously cooperating and competing both domestically and internationally, they have managed to maintain and promote their role as climate policy leaders. Although the level of ambition within leading German cities may be lower than in some other countries, especially in Northern Europe (Kern et al. 2021), they are still among the most ambitious cities in Europe, in particular with their aim to become climate neutral (Salvia et al. 2021).

Climate adaptation leaders (cluster 2) show a very similar profile to climate policy leaders (cluster 1), but at a somewhat lower level. Some climate adaptation leaders, such as Karlsruhe (Difu - Deutsches Institut für Urbanistik 2015), started their mitigation initiatives later than the climate policy leaders, but engaged in adaptation around the same time or even earlier than the top performers in cluster 1. Except for a few big cities in this cluster, climate adaptation leaders are nationally or regionally oriented, rather than major European or global cities. Scoring relatively high on adaptation compared to mitigation may indicate local vulnerabilities: Dresden and Cologne have a long history and experience of flood events (e.g. Kreibich and Thieken 2009; Merz and Thieken 2009), while Karlsruhe and Worms face high exposure to heat due to their location in the Upper Rhine Drift, the warmest region in Germany, with record temperatures of $40.2^{\circ} \mathrm{C}$ in 2003 (Kunz-Plapp et al. 2016). The city of Offenbach hosts the headquarters of the German Meteorological Service (DWD) with more than 2000 employees, which may also influence its climate policy. With around 83,000 inhabitants, Worms is the best-scoring small city (ranked 24 out of 104 cities). The city took its first steps on mitigation back in the early 1990s, although at a rather low and internal level. Worms joined the Climate Alliance in 2006, signed the Covenant of Mayors in 2010 and published a climate mitigation and energy efficiency strategy in the same year. From 2011 onwards, the city hired 
a climate manager, financed by federal funding. Worms has experienced extreme heat exposure, and it became a signatory of Mayors-ADAPT in 2014, applied successfully for another federal grant and introduced an adaptation plan 2 years later. As the only small city among the climate adaptation leaders and best-scoring municipality among its peers, Worms could serve as a model for this group of municipalities.

Our study confirms that cities piggyback on their prior mitigation efforts when adopting adaptation policies (Göpfert et al. 2019a; Grafakos et al. 2019; Lee et al. 2020). However, balancing mitigation and adaptation policies is challenging, particularly if a city has always focused strongly on mitigation. Freiburg, the first German city to set up an energy plan in 1986, is a case in point. Freiburg has probably attracted more international attention than any other German city as a centre of the green economy and a research hub for environmental and energy research among academics and practitioners alike (e.g. Medearis and Daseking 2012; Kronsell 2013; Affolderbach et al. 2019). However, the city cannot be found among the climate policy leaders in cluster 1 ; instead it is one of the climate mitigation leaders in cluster 3. Freiburg scored highest of all 104 cities in mitigation but only published an adaptation strategy in 2019 - several years after the best-scoring mid-sized climate policy leaders, Münster and Rostock. Thus, in contrast to the observation that a strong performance on mitigation makes a city more likely to undertake adaptation actions (Lee et al. 2020), the Freiburg case demonstrates that path dependency in mitigation can lead to lock-in situations that delay engagement with adaptation.

The group of climate mitigation leaders contains three small cities (Kaiserslautern, Emden and Kempten; see Fig. 6), all of which are so-called 'Masterplan communities' (MasterplanKommunen) (Difu - Deutsches Institut für Urbanistik 2017). These cities successfully participated in a competitive scheme set up by the German federal government that supports local mitigation policy financially and requires the development of a plan for becoming carbon neutral by 2050 . Thus, smaller cities can become climate mitigation leaders or pioneers, although perhaps only under certain conditions (see also Wurzel et al. 2019). In these cases, external funding from the federal and Länder governments provided the necessary jump-start to build capacity and develop policy. If funding programmes focus either on mitigation or adaptation, small cities may be able to make considerable progress in one field, but might lack the capacities to develop mitigation and adaptation policies simultaneously. As previous studies have identified (Eckersley 2018; Wurzel et al. 2019; Kern 2019), the availability of funding seems to be the best way to create incentives for latecomers and even laggards to develop strategies, set ambitious goals and join the group of climate policy followers or even become a climate mitigation or adaptation leader.

Most cities in cluster 4 started to tackle climate change issues relatively late. Those latecomers with enough capacity to join the group of climate policy followers have the advantage that they can institutionalize both areas of climate policy simultaneously. The example of the mid-sized city of Würzburg demonstrates that latecomers can develop balanced approaches and improve their performance substantially in a rather short period. Würzburg only joined the Climate Alliance in 2008, reorganized its environmental office in 2009, hired a climate manager in 2010 and set up an integrated mitigation and adaptation strategy in 2012 (Göpfert et al. 2019b).

Since only four cities with more than 200,000 inhabitants are among the 24 latecomers and 14 laggards, cities in these clusters may need substantial external support (in the form of funding and expertise) to catch up with the followers. Apart from funding programmes (e.g. for climate managers), this requires cooperation with local research institutions, as well as 
support from local and regional climate and energy agencies and national organizations (see also Kern et al. 2007; Reckien et al. 2015). As cities in clusters 5 and 6 are primarily regionally and nationally oriented, they are probably more interested in networking at the regional and national levels than internationally. Thus, they need appropriate German models such as the city of Worms. In keeping with studies of US cities (e.g. Krause 2011), transformation towards a carbon-neutral and climate-adapted city is even more challenging in those small and midsized cities that have historically been dominated by coal mining, coal-based energy production and steel-making (e.g. Cottbus, Salzgitter) or by the car industry (e.g. Ingolstadt, Wolfsburg).

We conclude that size, history and resources matter most for the creation of local mitigation and adaptation policy. First, bigger cities are in a far better position due to their superior capacities, which they can deploy to make local initiatives work and to engage in (international) networks. Second, climate policy leadership is path dependent, i.e. today's leading cities (cluster 1) have worked on climate issues for almost 30 years and have been able to balance mitigation and adaptation policies. Third, as already highlighted in the literature (Kern et al. 2007; Reckien et al. 2015; Grafakos et al. 2020), cities depend strongly on external funding and advice. While big cities are in a much better position to attract external funding, including EU funding, medium-sized and particularly smaller cities depend on tailor-made funding programmes, set up by the federal and the Länder governments, for developing and implementing integrated climate strategies.

For both indexes, information was only collected until the end of 2018. Since then, the field of mitigation and (to a lesser degree) adaptation has been highly dynamic. After the Fridays for Future movement became increasingly active in Germany (Marquardt 2020), around one-third of the 104 cities declared a climate emergency and/or increased their mitigation goals. Even where the council did not declare a climate emergency, many cities decided on alternative proposals and new policies, operating procedures or initiated organizational reforms. Next to this, the key climate funding instrument for municipalities in Germany, the so-called Kommunalrichtlinie, formerly supported both mitigation and adaptation plans. Currently, however, it now only covers the development of mitigation plans, and there is no comparable funding scheme for supporting adaptation plans. Against this backdrop, it is still unclear how the climate movement and revisions to crucial funding programmes will affect climate policy in German cities, because both developments put more emphasis on mitigation. To a lesser extent, the very hot and dry summers of 2018 and 2019 (Mücke and Litvinovitch 2020) increased the importance of adaptation in many cities, resulting in some cases in the development of municipal heat action plans. Thus, it seems worth repeating this analysis in a few years to get a better understanding of how protest movements, extreme weather events or changes to funding programmes may be affecting the relationship between mitigation and adaptation.

Next to this, a closer look at the distribution of cities and their cluster affiliation throughout Germany (see Fig. 6) could be of interest for future studies. For example, out of ten cities in Baden-Württemberg, only two are in cluster 5 and none in cluster 6 , whereas four of our 16 Bavarian cities are in cluster 5 and six of them are in cluster 6 . This might be partly explained by city size: in Bavaria, almost half of our 16 cities are small, whereas in Baden-Württemberg, eight of the ten in our sample are medium-sized (see Fig. 6). Further studies should examine the influence of specific funding schemes and policies at the federal state (Land) level on the development of municipal climate policies, to add to our knowledge of the factors that may support or hinder urban climate activities. Some states such as Baden-Württemberg are far more active than others in setting up funding schemes, offering awards for forerunners or 
negotiating climate accords between the state government and the associations of cities and towns.

Our study is limited in a number of ways. First, we only investigated cities with more than 100,000 inhabitants, or small independent cities; thus we cannot draw any conclusions about the activities of smaller cities or municipalities within county boundaries (although we assume they are generally less active than larger urban areas). Second, the mitigation and adaptation scores are composed differently. As there are fewer networks and competitions in the field of adaptation due to its more recent development, the adaptation score is based on fewer data sources and therefore might be less robust. Since this different assessment also affects our overall assessment of the policy field, we applied the min-max scaling to minimize the impact. Third, it is very difficult to capture and compare data relating to the actual implementation of climate activities (Reckien et al. 2015), and thus we barely included these factors in our study (except for the sub-indicator related to winning competitions). Estimating whether cities 'walk the walk', or if planned or implemented measures are at all meaningful in particular urban contexts, was therefore beyond the scope of our analysis. Future studies should discuss how to integrate implementation in such assessments. Fourth, cities might introduce initiatives without labelling them as mitigation or adaptation measures, and these would not be covered in our analysis. For example, flood protection measures from river floods are usually not part of urban adaptation actions in Germany, since the federal states (Länder) are largely responsible for this issue, rather than individual municipalities. In Passau, which does not gain any points for either mitigation or adaptation (see SI 1 ), many flood protection measures were planned and implemented after a serious flood event in 2013 (Wasserwirtschaftsamt Deggendorf 2017). Furthermore, the assessment and management of river floods are covered by the European Floods Directive (2007/60/EC) and the Federal Water Act (Wasserhaushaltsgesetz) including regular updates due to climate change. This is not the case for other hazards such as storms, heat or heavy rainfall (pluvial floods). Notwithstanding the importance of flood protection measures in Passau, cities that undertake traditional tasks and responsibilities in their administration, such as civil protection or the maintenance of green spaces, but do not consider these in the context of climate adaptation, might overlook new, emerging or changing risks.

\section{Conclusions}

In this paper, we developed an approach to rank and compare mitigation and adaptation activities in a large number of urban authorities, combined the results of both rankings and grouped the cities accordingly. Although some of the indicators may be specific to Germany, we nonetheless hope that the principles upon which we have based our index can also be applied in other jurisdictions. We suggest that this analysis is repeated after some years to detect developments and effects, e.g. of policy changes or extreme weather events.

Although cities with mitigation policies also tend to be engaged in adaptation, mitigation leaders are not always leading in the latter field. Instead, we presented six engagement types, from leaders to laggards, and discussed several reasons why cities might lead or lag in one or both fields. In line with the literature (Reckien et al. 2015; Salvia et al. 2021), we stress that city size is a crucial factor for leading in the field of mitigation and adaptation. However, size seems to matter most for the big forerunner cities on the one hand and small latecomer and laggard cities on the other, whereas all six clusters include mid-sized cities. While almost all 
cities in our sample are taking some action to mitigate climate change, adaptation is less common, partly due to it being a more recent topic.

Our analysis reveals the existence of three types of climate leadership among German cities: climate policy leaders, which lead in both areas; climate adaptation leaders, which have a very good record in mitigation but put more emphasis on adaptation; and climate mitigation leaders, which pursue the most ambitious goals in the area of climate mitigation but neglect climate adaptation. Due to the limited financial autonomy of German cities, external financial support from the federal states (Länder) and the national government is crucial to ensure that municipalities can introduce more ambitious policies, especially for smaller cities and adaptation measures. Our study shows that coping with climate change in a balanced way, taking synergies and trade-offs between mitigation and adaptation into account, depends on structural factors, in particular city size, the pathways of local climate policies since the $1990 \mathrm{~s}$ and, in the absence of mandates and hard regulation, funding programmes for both climate mitigation and adaptation.

Supplementary Information The online version contains supplementary material available at https://doi.org/ 10.1007/s10584-021-03142-9.

Acknowledgements The authors would like to thank Julia Dierck, Janne Irmisch and Stefan Schmidt for supporting this study by researching data for some of the indicators.

Code availability Not applicable.

Author contribution All authors contributed to the study conception and design. Material preparation, data collection and analysis were performed by all authors. All authors wrote different sections of the first draft of the manuscript, and all authors commented on previous versions of the manuscript. All authors read and approved the final manuscript.

Funding Open Access funding enabled and organized by Projekt DEAL. This study was developed within the framework of the joint research project 'Urban resilience against extreme weather events-typologies and transfer of adaptation strategies in small metropolises and medium-sized cities' (ExTrass) funded by Germany's Federal Ministry of Education and Research (BMBF, FKZ 01LR1709A1 and FKZ 01LR1709B1).

Data availability Supplementary 1 and 2 provide an overview of the data and their sources.

\section{Declarations}

Competing interests The authors declare no competing interests.

Open Access This article is licensed under a Creative Commons Attribution 4.0 International License, which permits use, sharing, adaptation, distribution and reproduction in any medium or format, as long as you give appropriate credit to the original author(s) and the source, provide a link to the Creative Commons licence, and indicate if changes were made. The images or other third party material in this article are included in the article's Creative Commons licence, unless indicated otherwise in a credit line to the material. If material is not included in the article's Creative Commons licence and your intended use is not permitted by statutory regulation or exceeds the permitted use, you will need to obtain permission directly from the copyright holder. To view a copy of this licence, visit http://creativecommons.org/licenses/by/4.0/. 


\section{References}

Affolderbach J, O’Neill K, Preller B (2019) Global-local tensions in urban green neighbourhoods: a policy mobilities approach to discursive change in Freiburg, Vancouver and Luxemburg. Geogr Ann B 101(4): 271-290. https://doi.org/10.1080/04353684.2019.1681286

Araos M, Berrang-Ford L, Ford JD, Austin SE, Biesbroek R, Lesnikowski A (2016) Climate change adaptation planning in large cities: a systematic global assessment. Environ Sci Pol 66(July):375-382. https://doi.org/ 10.1016/j.envsci.2016.06.009

Araos M, Ford J, Berrang-Ford L, Biesbroek R, Moser S (2017) Climate change adaptation planning for Global South megacities: the case of Dhaka. J Environ Policy Plan 19(6):682-696. https://doi.org/10.1080/ 1523908X.2016.1264873

Aylett A (2015) Institutionalizing the urban governance of climate change adaptation: results of an international survey. Urban Clim 14:4-16. https://doi.org/10.1016/j.uclim.2015.06.005

Balicia SF, Wright NG, van der Meulen F (2012) A flood vulnerability index for coastal cities and its use in assessing climate change impacts. Nat Hazards 64:73-105. https://doi.org/10.1007/s11069-012-0234-1

BBSR - Bundesinstitut für Bau- Stadt und Raumforschung. (2017) Laufende Stadtbeobachtung Raumabgrenzungen. https://www.bbsr.bund.de/BBSR/DE/forschung/raumbeobachtung/ Raumabgrenzungen/deutschland/gemeinden/StadtGemeindetyp/StadtGemeindetyp.html. Accessed 30th December 2020

Beatley T (2012) Green urbanism: learning from European cities. Island Press, Washington, DC

Berghausen M (2012) Hamburg - Wege zur klimafreundlichen und CO2-neutralen Großstadt. Informationen zur Raumentwicklung 5/6 2012:217-234

Bulkeley H (2010) Cities and the governing of climate change. Annu Rev Environ Resour 35:229-253. https:// doi.org/10.1146/annurev-environ-072809-101747

Bulkeley H, Kern K (2006) Local government and the governing of climate change in Germany and the UK. Urban Stud 43(12):2237-2259. https://doi.org/10.1080/00420980600936491

Castan Broto V, Bulkeley H (2013) A survey of urban climate change experiments in 100 cities. Glob Environ Chang 23(1):92-102. https://doi.org/10.1016/j.gloenvcha.2012.07.005

Davoudi S, Brooks E, Memood A (2013) Evolutionary resilience and strategies for climate adaptation. Plan Pract Res 28(3):307-322. https://doi.org/10.1080/02697459.2013.787695

Dierck J (2016) Wie reagieren Städte auf den Klimawandel? Eine Analyse von Klimaschutz- und Klimaanpassungsstrategien deutscher Mittel- und Großstädte. master thesis, Universität Potsdam

Difu - Deutsches Institut für Urbanistik (2015) Klimaschutz \& Klimaanpassung. Köln

Difu - Deutsches Institut für Urbanistik (2017) Akteure im kommunalen Klimaschutz erfolgreich beteiligen. Von Masterplan-Kommunen lernen, Berlin

Difu - Deutsches Institut für Urbanistik (2020) Ausgezeichnete Praxisbeispiele. Klimaaktive Kommune 2019. Köln

Eckersley P (2018) Who shapes local climate policy? Unpicking governance arrangements in English and German cities. Environ Polit 27(1):139-160. https://doi.org/10.1080/09644016.2017.1380963

Eckersley P, England K, Ferry L (2018) Sustainable development in cities: collaborating to improve urban climate resilience and develop the business case for adaptation. Public Money Manag 38(5):335-344. https://doi.org/10.1080/09540962.2018.1477642

Emelianoff C (2014) Local energy transition and multilevel climate governance: the contrasted experiences of two pioneer cities (Hanover, Germany, and Växjö, Sweden). Urban Stud 51(7):1378-1393. https://doi.org/ 10.1177/0042098013500087

Ford JD, Berrang-Ford L (2016) The 4Cs of adaptation tracking: consistency, comparability, comprehensiveness, coherency. Mitig Adapt Strat G1 21(6):839-859. https://doi.org/10.1007/s11027-014-9627-7

Ford JD, Berrang-Ford L, Biesbroek R, Araos M, Austin SE, Lesnikowski A (2015) Adaptation tracking for a post-2015 climate agreement. Nat Clim Chang 5(11):967-969. https://doi.org/10.1038/nclimate2744

Fuhr H, Hickmann T, Kern K (2018) The role of cities in multi-level climate governance: local climate policies and the $1.5^{\circ} \mathrm{C}$ target. Curr Opin Environ Sustain 30:1-6

Göpfert C, Wamsler C, Lang W (2019a) Institutionalizing climate change mitigation and adaptation through city advisory committees: lessons learned and policy futures. City Environ Interact 1:100004. https://doi.org/10. 1016/j.cacint.2019.100004

Göpfert C, Wamsler C, Lang W (2019b) A framework for the joint institutionalization of climate change mitigation and adaptation in city administration. Mitig Adapt Strat Gl 24:1-21. https://doi.org/10.1007/ s11027-018-9789-9

Göpfert C, Wamsler C, Lang W (2020) Enhancing structures for joint climate change mitigation and adaptation action in city administrations - empirical insights and practical implications. City Environ Interact 8. https:// doi.org/10.1016/j.cacint.2020.100052 
Grafakos S, Pacteau C, Delgado M, Landauer M, Lucon O, Driscoll P (2018) Integrating mitigation and adaptation: opportunities and challenges. In: Rosenzweig C, Solecki W, Romero-Lankao P, Mehrotra S, Dhakal S, Ibrahim SA (eds) Climate change and cities: second assessment report of the urban climate change research network. Cambridge University Press, New York, pp 101-138

Grafakos S, Trigg K, Landauer M, Chelleri L, Dhakal S (2019) Analytical framework to evaluate the level of integration of climate adaptation and mitigation in cities. Clim Chang 154:87-106. https://doi.org/10.1007/ s10584-019-02394-w

Grafakos S, Viero G, Reckien D, Trigg K, Viguie V, Sudmant A, Graves C, Foley A et al (2020) Integration of mitigation and adaptation in urban climate change action plans in Europe: a systematic assessment. Renew Sust Energ Rev 121:109623. https://doi.org/10.1016/j.rser.2019.109623

Guyadeen D (2019) Evaluating the quality of municipal official plans in the Ontario-Greater Golden Horseshoe Region, Canada. J Plan Educ Res:121-143. https://doi.org/10.1177/0739456X19859648

Hamin EM, Gurran N (2009) Urban form and climate change: balancing adaptation and mitigation in the U.S. and Australia. Habitat Int 33(3):238-245. https://doi.org/10.1016/j.habitatint.2008.10.005

Hanson S, Nicholls R, Ranger N, Hallegatte S, Corfee-Morlot J, Herweijer C, Chateau J (2011) A global ranking of port cities with high exposure to climate extremes. Clim Chang 104:89-111. https://doi.org/10.1007/ s10584-010-9977-4

Haupt W (2020) How Do local policy makers learn about climate change adaptation policies? Examining study visits as an instrument of policy learning in the European Union. URBAN AFF REV, 107808742093844. https://doi.org/10.1177/1078087420938443

Haupt W, Chelleri L, van Herk S, Zevenbergen C (2020) City-to-city learning within climate city networks: definition, significance, and challenges from a global perspective. Int J Urban Sustain Dev 12(2):143-159. https://doi.org/10.1080/19463138.2019.1691007

Haupt W, Eckersley P, Kern K (2021) How can 'ordinary' cities become climate pioneers? In: Howarth C, Lane M, Slevin A (eds) Addressing the Climate CrisisLocal action in theory and practice. Springer, Berlin and Heidelberg

Heidrich O, Dawson RJ, Reckien D, Walsh CL (2013) Assessment of the climate preparedness of 30 urban areas in the UK. Clim Chang 120(4):771-784. https://doi.org/10.1007/s10584-013-0846-9

Heidrich O, Reckien D, Olazabal M, Foley A, Salvia M, de Gregorio HS, Orru H et al (2016) National climate policies across Europe and their impacts on cities strategies. J Environ Manag 168:36-45. https://doi.org/10. 1016/j.jenvman.2015.11.043

Heinelt H, Lamping W (2015) Wissen und Entscheiden: Lokale Strategien gegen den Klimawandel in Frankfurt a.M., München und Stuttgart. Campus, Frankfurt a.M./New York

Hunt A, Watkiss P (2011) Climate change impacts and adaptation in cities: a review of the literature. Clim Chang 104(1):13-49. https://doi.org/10.1007/s10584-010-9975-6

IPCC - Intergovernmental Panel on Climate Change (2014) Summary for policymakers. In: Edenhofer O, PichsMadruga R, Sokona Y, Farahani E, Kadner S, Seyboth K, Adler A, Baum I, Brunner S, Eickemeier P, Kriemann B, Savolainen J, Schlömer S, von Stechow C, Zwickel T, Minx JC (eds) Climate Change 2014: Mitigation of Climate Change. Contribution of Working Group III to the Fifth Assessment Report of the Intergovernmental Panel on Climate Change. Cambridge University Press, Cambridge

Jänicke M, Wurzel RKW (2019) Leadership and lesson-drawing in the European Union's multilevel climate governance system. Environ Polit 28(1):22-42. https://doi.org/10.1080/09644016.2019.1522019

Kern K (2019) Cities as leaders in EU multilevel climate governance: embedded upscaling of local experiments in Europe. Environ Polit 28(1):125-145. https://doi.org/10.1080/09644016.2019.1521979

Kern K (2020) Von Vorreitern und Nachzüglern: Die Rolle von Städten und Gemeinden in der Klimapolitik. In: Hickmann T, Lederer, M (eds.) Leidenschaft und Augenmaß. Sozialwissenschaftliche Perspektiven auf Entwicklung, Verwaltung, Umwelt und Klima. Baden-Baden: Nomos, pp. 195-205.

Kern K, Bulkeley H (2009) Cities, Europeanization and multi-level governance: governing climate change through transnational municipal networks. J Common Mark Stud 47(1):309-332

Kern K, Niederhafner S, Rechlin S, Wagner J (2005) Kommunaler Klimaschutz in Deutschland: Handlungsoptionen, Entwicklung und Perspektiven, Discussion Paper 2005/101. Berlin für Sozialforschung, Wissenschaftszentrum

Kern K, Koll C, Schophaus M (2007) The diffusion of Local Agenda 21 in Germany: comparing the German federal states. Environ Polit 16(4):604-624. https://doi.org/10.1080/09644010701419139

Kern K, Grönholm S, Haupt W, Hopman L, Tynkkynen N, Kettunen P (2021) Matching forerunner cities: assessing Turku's climate policy in comparison with Malmö, Groningen and Rostock, Research Report 1/2021, Turku Urban Research Programme.

Keskitalo C, Juhola S, Baron N, Fyhn H, Klein J (2016) Implementing local climate change adaptation and mitigation actions: the role of various policy instruments in a multi-level governance context. Climate 4(7). https://doi.org/10.3390/cli401000 
Kousky C, Schneider SH (2003) Global climate policy: will cities lead the way? Clim Pol 3(4):359-372. https:// doi.org/10.1016/j.clipol.2003.08.002

Krause RM (2011) Policy innovation, intergovernmental relations, and the adoption of climate protection initiatives by U.S. cities. J Urban Aff 33(1):45-60. https://doi.org/10.1111/j.1467-9906.2010.00510.x

Kreibich H, Thieken AH (2009) Coping with floods in the city of Dresden, Germany. Nat Hazards 51(3):423436. https://doi.org/10.1007/s11069-007-9200-8

Kronsell A (2013) Legitimacy for climate policies: politics and participation in the Green City of Freiburg. Local Environ 18(8):965-982. https://doi.org/10.1080/13549839.2012.748732

Kunz-Plapp T, Hackenbruch J, Schipper JW (2016) Factors of subjective heat stress of urban citizens in contexts of everyday life. NHESS 16(4):977-994. https://doi.org/10.5194/nhess-16-977-2016

Landauer M, Juhola S, Söderholm M (2015) Inter-relationships between adaptation and mitigation: a systematic literature review. Clim Chang 131(4):505-517. https://doi.org/10.1007/s10584-015-1395-1

Landauer M, Juhola S, Klein K (2019) The role of scale in integrating climate change adaptation and mitigation in cities. J Environ Pol Man 62(5):741-765. https://doi.org/10.1080/09640568.2018.1430022

Lee T, Koski C (2015) Multilevel governance and urban climate change mitigation. Environ Plan C Politics Space 33(6):1501-1517. https://doi.org/10.1177/0263774X15614700

Lee T, Yang H, Blok A (2020) Does mitigation shape adaptation? The urban climate mitigation-adaptation nexus. Clim Pol 20(3):341-353. https://doi.org/10.1080/14693062.2020.1730152

Lesnikowski A, Biesbroek R, Ford JD, Berrang-Ford L (2020) Policy implementation styles and local governments: the case of climate change adaptation. Environ Politics:1-38. https://doi.org/10.1080/09644016. 2020.1814045

Marquardt J (2020) Fridays for Future's disruptive potential: an inconvenient youth between moderate and radical ideas. Front Commun 5(48):1-18

Martire S, Mirabella N, Sala S (2018) Widening the perspective in greenhouse gas emissions accounting: the way forward for supporting climate and energy policies at municipal level. J Clean Prod 176:842-851. https://oi. org/10.1016/j.jclepro.2017.12.055

Massey E, Huitema D (2016) The emergence of climate change adaptation as a new field of public policy in Europe. Reg Environ Chang 16:553-564. https://doi.org/10.1007/s10113-015-0771-8

Measham TG, Preston BL, Smith TF, Brooke C, Gorddard R, Withycombe G, Morrison C (2011) Adapting to climate change through local municipal planning: barriers and challenges. Mitig Adapt Strat Gl 16:889-909. https://doi.org/10.1007/s11027-011-9301-2

Medearis D, Daseking W (2012) Freiburg, Germany: Germany's eco-capital. In: Timothy B (ed) Green Cities of Europe. Island Press, Washington et al., pp 65-82

Mees HLP, Driessen PPJ, Runhaar HAC (2012) Exploring the scope of public and private responsibilities for climate adaptation. J Environ Policy Plan 14(3):305-330. https://doi.org/10.1080/1523908X.2012.707407

Meijering J, Kern K, Tobi H (2014) Identifying the methodological characteristics of European city rankings. Ecol Indic 43:132-142. https://doi.org/10.1016/j.ecolind.2014.02.026

Merz B, Thieken AH (2009) Flood risk curves and uncertainty bounds. Nat Hazards 51(3):437-458. https://doi. org/10.1007/s11069-009-9452-6

Monstadt J (2007) Urban governance and the transition of energy systems: institutional change and shifting energy and climate policies in Berlin. Int J Urban Region 31(2):326-343. https://doi.org/10.1111/j.14682427.2007.00725.x

Mücke HG, Litvinovitch JM (2020) Heat extremes, public health impacts, and adaptation policy in Germany. Int J Environ Res Public Health 17:7862. https://doi.org/10.3390/ijerph17217862

Nicholls RJ, Hanson S, Herweijer C, Patmore N, Hallegatte S, Corfee-Morlot J., Château J, Muir-Wood R (2008) Ranking port cities with high exposure and vulnerability to climate extremes. OECD Environment Working Papers No. 1, doi:https://doi.org/10.1787/011766488208

Olazabal M, Hurtado SDG, Olazabal E, Pietrapertosa F, Salvia M, Geneletti D, D’Alonzo V, Feliú E, Di Leo S, Reckien, D. (2014) How are Italian and Spanish cities tackling climate change? A local comparative study. Basque Centre for Climate Change (BC3) Working Paper Series.

Pasimeni MR, Valente D, Zurlini G, Petrosillo I (2019) The interplay between urban mitigation and adaptation strategies to face climate change in two European countries. Environ Sci Pol 95:20-27. https://doi.org/10. 1016/j.envsci.2019.02.002

Reckien D, Flacke J, Dawson RJ, Heidrich O, Olazabal M, Foley A, HAmann JJP, Orru H, Salvia M, De Gregorio HS, Geneletti D, Pietrapertosa F (2014) Climate change response in Europe: what's the reality? Analysis of adaptation and mitigation plans from 200 urban areas in 11 countries. Clim Chang 122(1-2): 331-340. https://doi.org/10.1007/s10584-013-0989-8

Reckien D, Flacke J, Olazabal M, Heidrich O (2015) The Influence of drivers and barriers on urban adaptation and mitigation plans — an empirical analysis of European cities. PLoS One 10(8):1-21. https://doi.org/10. 1371/journal.pone.0135597 
Reckien D, Salvia M, Heidrich O, Church JM, Pietrapertosa F, De Gregorio Hurtado S, D’Alonzo V, Foley A, Simoes SG, Lorencova EK et al (2018) How are cities planning to respond to climate change? Assessment of local climate plans from 885 cities in the EU-28. J Clean Prod 191(2018):207-219. https://doi.org/10.1016/j. jclepro.2018.03.220

Reckien D, Salvia M, Pietrapertosa F, Simoes SG, Olazabal M, De Gregorio HS et al (2019) Dedicated versus mainstreaming approaches in local climate plans in Europe. Adv Mater Res_Switz 112:948-959. https://doi. org/10.1016/j.rser.2019.05.014

Rosenzweig C, Solecki W, Hammer SA, Mehrotra S (2010) Cities lead the way in climate-change action. Nature 467(7318):909-911. https://doi.org/10.1038/467909a

Runhaar H, Wilk B, Person Å, Uittenbroeck C, Wamsler C (2017) Mainstreaming climate adaptation taking stock about "what works" from empirical research worldwide. Reg Environ Chang 18:1201-1210. https:// doi.org/10.1007/s10113-017-1259-5

Salvia M, Reckien D, Pietrapertosa F, Eckersley P, Spyridaki NA, Krook-Riekkola A, OLazabal M, Gregorio DE, Hurtado S, Simoes SG (2021) Will climate mitigation ambitions lead to carbon neutrality? An analysis of the local-level plans of 327 cities in the EU. Renew Sust Energ Rev 135. https://doi.org/10.1016/j.rser. 2020.110253

Sharifi A (2020) Trade-offs and conflicts between urban climate change mitigation and adaptation measures: a literature review. J Clean Prod 276:122813. https://doi.org/10.1016/j.jclepro.2020.122813

Sharifi A (2021) Co-benefits and synergies between urban climate change mitigation and adaptation measures: A literature review. Sci Total Environ 750. https://doi.org/10.1016/j.scitotenv.2020.141642

Spekkers M, Rözer V, Thieken A, ten Veldhuis MC, Kreibich H (2017) A comparative survey of the impacts of extreme rainfall in two international case studies. Nat Hazard Earth Sys 17:1337-1355. https://doi.org/10. 5194/nhess-17-1337-2017

Sullivan R, Gouldson A, Webber P (2013) Funding low carbon cities: local perspectives on opportunities and risks. Clim Pol 13(4):514-529. https://doi.org/10.1080/14693062.2012.745113

Thieken A, Dierck J, Otto A (2018) Deutschlandweiter Überblick zu städtischen Klimaschutz- und Klimaanpassungskonzepten. In: Thieken A et al (eds) Verbundvorhaben "Zukunftsstadt" (Definitionsprojekt). Urbane Resilienz gegenüber extremen Wetterereignissen - Typologien und Transfer von Anpassungsstrategien in kleinen Großstädten und Mittelstädten (ExTrass). Universität Potsdam

Toly NJ (2008) Transnational municipal networks in climate politics: from global governance to global politics. GLOBALIZATION 5(3):341-356. https://doi.org/10.1080/14747730802252479

Wang D, Du Z, Wu H (2020) Ranking global cities based on economic performance and climate change mitigation. Sustain Cities Soc 62:102395. https://doi.org/10.1016/j.scs.2020.102395

Wasserwirtschaftsamt Deggendorf (2017) Hochwasserschutz der Stadt Passau. Fortschreibung der Machbarkeitsstudie, Deggendorf

Woodruff SC, Stults M (2016) Numerous strategies but limited implementation guidance in US local adaptation plans. NAT CLIM CHANGE, 6(8), 796-802. https://doi.org/10.1038/nclimate3012

World Bank (2010) Cities and Climate: Change: An Urgent Agenda. http://hdl.handle.net/10986/17381. Accessed 3rd January 2021

Wurzel RKW, Moulton JFG, Osthorst W, Mederake L, Deutz P, Jonas AEG (2019) Climate pioneership and leadership in structurally disadvantaged maritime port cities. Environ Politics 28(1):146-166. https://doi.org/ $10.1080 / 09644016.2019 .1522039$

Publisher's note Springer Nature remains neutral with regard to jurisdictional claims in published maps and institutional affiliations. 